\title{
Design and Implementation of Information Management System for Enterprise
}

\author{
Dong Xin ${ }^{\mathrm{a}}$, Hongxia Zhao ${ }^{\mathrm{b}}$, Baogang Zhou ${ }^{\mathrm{c}}$ \\ School of Management, Bohai University, Jinzhou, P.R. China \\ adxbhdx@163.com, b64071435@qq.com, ${ }^{\mathrm{c}}$ 80891137@qq.com
}

Keywords: Enterprise information; NET three-layer framework; feasibility analysis; management system; functional design

\begin{abstract}
With the rapid development of economic construction and the further development of enterprise information, computer and network technology are gradually applied to enterprises to improve efficiency and quality, and information management is an important part of modern enterprise management, so the design and implementation of enterprise information management system is important. Firstly, this paper describes the feasibility analysis of enterprise information management systems, including technical feasibility, economic feasibility and operational feasibility; secondly, studies the technical framework for the design of enterprise information management systems, mainly based on the .Net three-layer framework; finally describes the functional design of each module in the system. Analysis and design of enterprise information management system solves the common problems faced in the process of development and growth of enterprise, improving work efficiency and reducing operating costs.
\end{abstract}

\section{Introduction}

Under the background of information era, this office method by the paper as a medium has been unable to adapt to the demands of the era, for enterprises, which spent even more human and material resources, follow the development of era, is bound to adopt computer mode to manage information. Enterprise information management is that enterprise in order to maximize fully use of existing resources, strives to improve the quality of production and operation, all activities which in order to maximize obtain the economic benefits as the purpose, the process of approach implementing. In this process, business operators according to their enterprises characteristics continually to summarize, summarize, improving management and methods, trying to reach the harmony of entire enterprise's internal and external environment [1].

Information management system for enterprise (EMS) is a management system that uses of modern management ideas and methods, computer as a carrier, using computer software and network communication technology, in the process of production, management and decision-making collecting, storing, processing and analyzing a variety of information, to help companies process daily businesses until decision alternatives developed and the work optimized, as well as tracking, monitoring, controlling and regulating [2]. In general enterprise information management system consists of two parts that is office class and business systems, has five properties, including characteristics of industry experts and practical application characteristics, systematic and holistic, accumulation and sharing of history knowledge, and decision-making supportive and dynamic characteristics adapt to information changes. A complete enterprise information management system has a good support and protection role for production and business activities of enterprises, specifically shows in the various departments within the enterprise clear responsibilities, collaboration, achieves paperless office, adjust and optimize the internal departments, make accurate predictions for the market development, etc. [3]. 


\section{Feasibility Analysis}

Feasibility analysis of a project mainly includes several aspects, such as the necessity, feasibility, and rationality and so on. Mainly explore the possibility and necessity of solving the problem, try to high-efficiency models and lower costs to estimate whether can be solved. Feasibility analysis primarily uses large amounts of data, information and other items of information to evaluate the feasibility of project created, there are several factors, namely the analysis method is comprehensive, system; second, economic efficiency as the core; third is to fully take into account other factors that could affect the project [4]. This paper mainly analyses three aspects that is the economic feasibility, technical feasibility and operational feasibility.

Economic feasibility mainly measures the value of the project from the perspective of resource allocation, perform cost estimates and revenue estimates, depending on whether the economic benefits of the system can exceed the cost required to develop and maintain, as well as part of the social benefit needs experience to estimate. In the system design and operation, in addition to the server requires a little higher, the terminal equipment is not very expensive. Function needed by system is not more so developed up is simple, short development cycle, easy to learn, training of personnel funds will not be many, so the aspect of economic is feasible.

Technical feasibility mainly from the technical point of implementation rationally design technical solutions, and make comparison and evaluation. Research on project technical feasibility of different industries and the depth varies greatly. This system uses the ASP.NET development. ASP.NET framework is based on a common language of the program running on the server, greatly improving the efficiency, because it is compiled based on the common language runtime, so it has a powerful and adaptable, also easy to learn, efficient and manageable [5]; Therefore, this paper studied the enterprise information management system with technical feasibility.

Operational feasibility mainly analysis two points, from the user point, rational functional module design and convenient operation, fully meet the needs of users; from the administrator perspective, rational functional modules design facilitates internal management for system administrator. User interface design of the system is relatively simple, user-friendly use, company's employees through a brief training will be able to independently use of the system. Therefore, in terms of the operation, development of the system is feasible [6].

\section{Technical Framework Design}

The another goal of framework design is that guarantee the scalability of system requirements for late, because with the continuous development of business and technology, the expansion of the system is essential, so in the process of system design, the goals of system architecture design include the following several aspects: (1) reasonable, each system has its own characteristics, has its own unique features and achieve results, in the design should not blindly pursue the new structure and new technologies, but to meet its own, to select the most suitable; (2) reuse, in the development appropriately pursuit the reusing between components and design patterns can greatly shorten the development cycle; (3) maintainability, architecture design need to rationally use theoretical knowledge of design patterns, to follow "high cohesion, low coupling" design thinking, enhance the maintainability of the code. (4) The scalability and portability; (5) performance, which is one of the core of a mature framework available, for long service and support a large number of access and speed of response is particularly important; (6) security, the framework design must be introduced NSPA access authentication mechanism [7].

The development of system using .Net three-tier structure, each business function is divided into three levels, the uppermost layer is the user layer, it facing the system user, providing visibility, actionable, friendly functional interface, users do not care these functions are how to achieve; the middle layer is business logic layer, the layer is mainly obtains the data input by user in the interface, by the business logic judgment, or calculating the data in the database, to a certain form feedback to the user interface, for users to browse, it can be said, business logic layer mainly 
explains the function is how to achieve; the bottom is the data access layer, the layer is firstly taken data processing results from the middle layer, and then executed to add, delete, change, and other operations for the database, finally, the results will be fed back to the business logic layer for the intermediate layer processing [8]. Advantages of three-tier architecture include clear structure, low degree of coupling, easy system maintenance and expansion and helping the development tasks simultaneously. Overall technical architecture of the system is shown in Fig. 1.

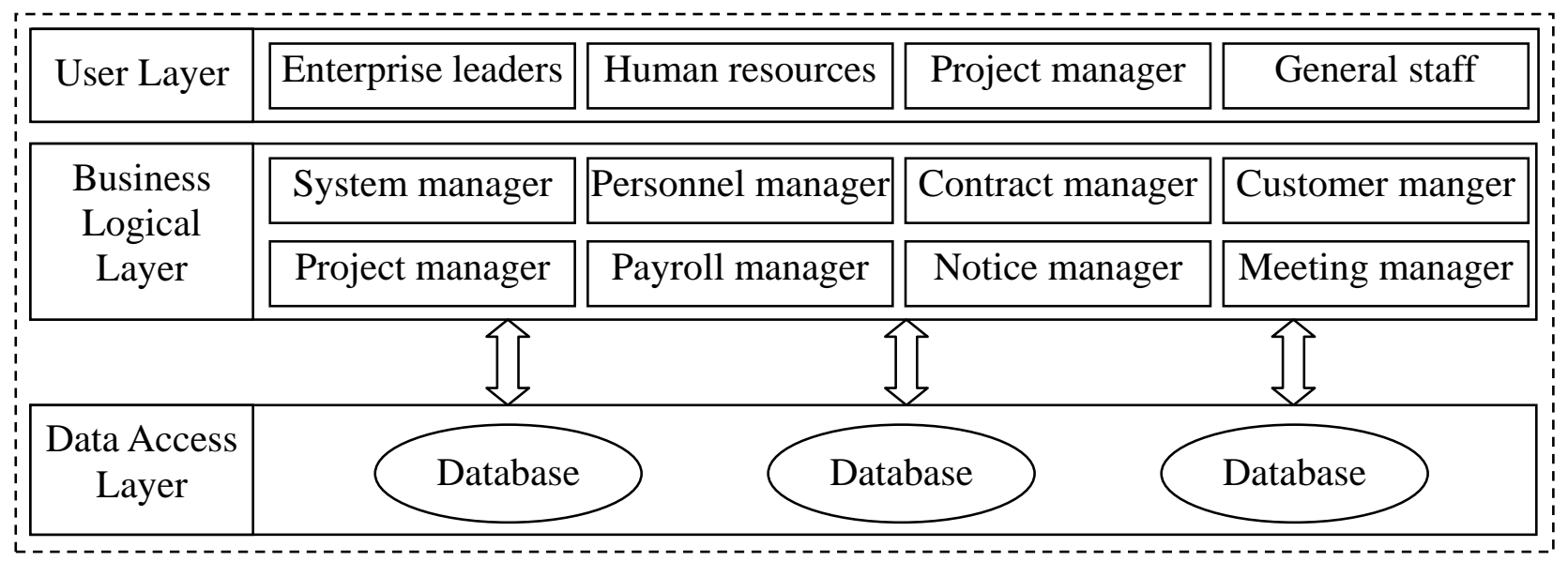

Fig. 1. Enterprise information management system architecture diagram

\section{Functional Design}

In this paper, the analysis and design of enterprise information management system is mainly based on the following principles: (1) the principle of integrity that is the overall planning, distribution development; (2) the principle of practicality, usability refers to maintaining the system and their actual business activity the same or similar degree, it is decisive factor to decided systems development success; (3) interface design principles, interface design beautiful, friendly, easy to operate, user-friendly design to comply with the principles; (4) modular design principle, using modular programming mode, the system is divided each module according to the function, so that the system has good scalability; (5) scalable principles; (6) the security principle [9]. The system includes system management, personnel management, contract management, customer management, project management, payroll management, bulletin management and conference management eight functional modules. Functional block diagram of the system is shown in Fig. 2.

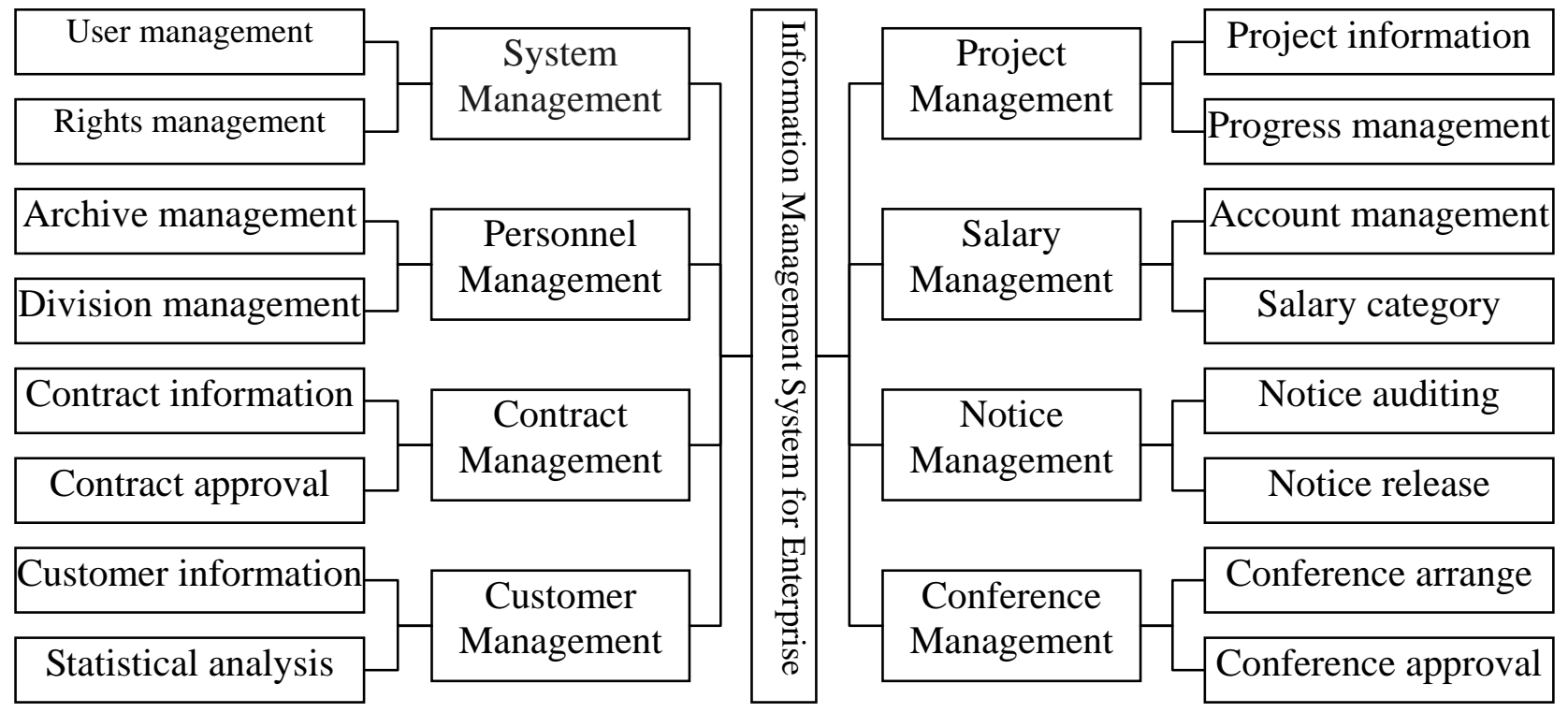

Fig. 2. Enterprise information management system functional block diagram 
System management module mainly achieves that system administrator maintains for system information, database backup, access control and other functions, including user management, privilege management, and password changes three sub-modules; personnel management modules include staff management and departments management two sub-modules, where staff management is divided into employee records management, employee mobility management, employee training management, employee incentive management and employee appraisal management; customer management module mainly achieves all of the maintenance of company's customer data; contract management module implemented the management of customer contract information; project management module mainly implements the monitor of enterprise project and the management of project information; payroll management module mainly achieves the management of employee wages, including six sub-modules; the function of bulletin management module mainly includes inform the enterprise bulletin, modify, query, and delete; conference management module provides a record of the daily meetings.

\section{Conclusion}

The development of information science and technology promotes the development of science and technology, economy and society, and the progress of science and technology, economic has created favorable conditions for the information technology work to bring about change. In this context, the impact of management information systems for enterprises is increasing [10]. Enterprise information management system designed in this article achieves interacting and sharing of information for people, the office's efficiency has been greatly improved, break the previous state where paper-office people busy and inefficient, effectively solved a range of issues in the development process due to changing requirements, or to expand system function [11], the original messy workflow simplicity, standardization, improve employee productivity, saving management costs, creating valuable information, it should be promoted in the future commercial development.

\section{References}

[1] X. Y. Zeng, "Enterprise Information Management," Science Press, 2007.

[2] G. X. Gao, "Enterprise Information Job Log Management System," Hunan University Press, 2007.

[3] H. L. Zhou, "The Design and Implementation of Enterprise Information Management System Based On SSI2," Master's Degree of University of Electronic Science and Technology of China, 2012.

[4] H. Yin, "Design and Implementation of Information Management System of Enterprise Based on Web technology," Master's Degree of Jilin University, 2013.

[5] L. Zhou, "Design of Enterprise Infermation Management System for M\&S," Master's Degree of Yunnan University, 2010.

[6] J. Zhang, "Project Management for Information System Integration," Inner Mongolia Science Technology \& Economy, vol. 15, no. 9, pp. 69-70, 2011.

[7] Y. Wang, "The Design and Implementation of Management System for Enterprise Information," Master's Degree of Donghua University, 2014.

[8] H. Z. Liu, "Design and Implementation of Information Management System for Enterprise," Master's Degree of University of Electronic Science and Technology of China, 2011.

[9] P. C. Yao, "Research and Implementation of Enterprise Information Management System," Master's Degree of University of Electronic Science and Technology of China, 2013. 
[10] X. Guo, "The Realization of Enterprise Information Management System," Manufacturing Automation, vol. 33, no. 8, pp. 19-20, 2011.

[11] Y. Z. Ren, X. C. Wang, "Design and Research of Enterprise Information Management System Based On SSH Framework," Science \& Technology Information, vol. 10, no. 1, pp. 15-16, 2012. 